\begin{tabular}{c} 
Brazilian Journal \\
of Chemical \\
Engineering \\
\hline
\end{tabular}

ISSN 0104-6632

Printed in Brazil

www.abeq.org.br/bjche

Vol. 26, No. 01, pp. 23 - 31, January - March, 2009

\title{
THE USE OF STYRENE-BUTADIENE RUBBER WASTE AS A POTENTIAL FILLER IN NITRILE RUBBER: ORDER OF ADDITION AND SIZE OF WASTE PARTICLES
}

\author{
D. A. Baeta ${ }^{1}$, J. A. Zattera ${ }^{2}$, M. G. Oliveira ${ }^{3}$ and P. J. Oliveira ${ }^{1 *}$ \\ ${ }^{1}$ Departamento de Engenharia Química, Universidade Federal Rural do Rio de Janeiro, Seropédica, \\ Fax: + (55) (21) 3787-3750, 23890-000, Rio de Janeiro - RJ, Brazil. \\ E-mail: pjansen@ufrrj.br \\ ${ }^{2}$ Universidade de Caxias do Sul, Centro de Ciências Exatas e Tecnologia, Departamento de Engenharia Químicas, \\ Fax: + (55) (54) 3218-2160, 9500-1970, Caxias do Sul - RS, Brazil. \\ E-mail: azattera@terra.com. br. \\ ${ }^{3}$ Instituto Nacional de Tecnologia, Fax: + (55) (21) 2123-1064, Avenida Venezuela 82, \\ Saúde, 20081-312, Rio de Janeiro - RJ, Brazil. \\ E-mail: marciago@int.gov.br
}

(Submitted: November 13, 2007 ; Revised: May 8, 2008 ; Accepted: May 14, 2008)

\begin{abstract}
Styrene-butadiene rubber (SBR) has large applications in the shoe industry, especially as expanded sheets used to produce insoles and inner soles. According to TG analysis, the rubber content in SBR residues (SBR-r) was found to be around 26-wt\%. Based on that data, a cost-effective technique for the reuse of SBR$r$ in Nitrile rubber (NBR) was developed. Later, the effect of SBR-r on the cure behavior, mechanical performance, swelling, and crosslink density of reused rubber was investigated, with more emphasis placed on the effect of both particle size and loading of waste filler. Cure characteristics such as optimum cure time and scorch time were then reduced by the increasing amount of SBR-r filler. Owing to the reinforced nature of the largest particle size SBR-r, the best results for the mechanical properties of NBR were those in which SBR-r was added at the end of the cure process. The study has thus shown that SBR residue (SBR-r) can be used as an economical alternative filler in NBR.

Keywords: Vulcanization; Adhesion; Elastomer; Cure.
\end{abstract}

\section{INTRODUCTION}

The perfection of industrial processes and the development of new formulations for rubber have contributed to the significant increase in residue amount and type. The main source of waste rubber is discarded rubber products, such as discarded tires, rubber pipes, rubber belts, rubber shoes, edge scraps, waste products that are produced in rubber processes and others (Fang and et al 2001). Thus, the disposal of rubber waste is a serious economic and ecological problem.
In recent years, the polymer industry has developed an interest in the improvement of cost-effective techniques to convert waste and used rubber into a processable form (Harshaft, 1972; Lee and Millem, 1977; Braton and Koutsky, 1974, Phadke et al 1983). Researchers have used various techniques such as chemical, thermo-mechanical, and cryomechanical processes (Ratcliffe, 1977 and Biddulph, 1977.) The earlier approach to this problem was to reclaim or remove the crosslinks in rubber rejects and then use the latter as new rubber. However, the use of reclaimed rubber was limited owing to three main reasons:

*To whom correspondence should be addressed 
(i) In the case of waste tires, easy reclamation was not possible due to the presence of steel belts or plies (Rajalingam, 1983.)

(ii) The properties of reclaimed rubber are inferior due to degradation of the chains of polymer during processing (Mathew, 2001.)

(iii) After the process of reclamation, components of the mixture responsible for certain properties are inefficient (Acetta, 1981.)

Many reviews regarding the disposal problem of rubber rejects and possible solutions are available in the literature (Phadke, 1984; Phadke, 1985; Claramma, 1986; Azzir, 1990). Zhan et al (2001) discuss the significance of recycling rubber waste to protect the environment and to conserve energy. The use of cryoground rejects as filler in rubbers and polyolefins is well known (Oliphant, 1993). Recently, several new methods for the devulcanization of rubber waste have become available, but the most important one among these is the devulcanization process using ultrasonic irradiation. Studies in this field (Tukachinsky, 1996; Levin, 1996; Isayev et al., 1995 and Isayev et al., 1996) have found that, in the presence of heat and temperature, ultrasonic waves were able to break up the three-dimensional network in cross-linked rubbers. The resulting devulcanised rubber could then be reprocessed, shaped, and revulcanised just like virgin rubber. Chemical, mechanical, plasma, corona and electron-beam radiation were reported to be useful in improving matrix-filler adhesion (Fujimoto, 1979; Creasey and Wager, 1968; Fujimoto et al., 1981, Yasuda et al., 1977; Zimmermann et al., 199 and Yu et al., 1992).

The adoption of new materials and modern processes of footwear manufacture have increased the production and efficiency of the sector. However, it has also resulted in augmented production of residues. It is estimated that 3 million tons of residues are produced annually in the processing stage alone. However, residue amounts have grown on the same scale.

Styrene Butadiene Rubber residues (SBR-r) present a great potential for use as load in elastomeric formulations. In its formulation, this residue contains expanding agent and curatives, besides inorganic loads (Sombatsompop, 1999; Sakai, 1991 and Tatiböuet et al., 2004). When properties such as tensile strength and tearing and abrasion resistance are compared with the same rubber compositions without load (Saxena et al., 1999), they reflect reinforcement in the elastomer proceeding from fillers.

In this article, we report on a cost-effective method to reuse SBR residues as fillers in nitrile rubber (NBR), as well as the influence of load on the cure characteristics. Emphasis has been given to the effect of particle size, addition order and the effect of the amount of SBR-r on mechanical properties. Swelling studies have also been carried through to understand the interaction of SBR waste filler and NBR matrix.

\section{EXPERIMENTAL}

\section{Materials}

NBR (NBR615-B) (33 wt \% of acrylonitrile; Mooney viscosity $=47$ ) was kindly supplied by NITRIFLEX S.A., Rio de Janeiro, Brazil. Styrene Butadiene Rubber residues (SBR-r) (density = $0.9006 \mathrm{~g} / \mathrm{cm}^{3}$; gel amount $=93.04 \%$ ) was kindly supplied by a footwear industry from Caxias do SulRS, Brazil. Rubber additives were as follows: zinc oxide, stearic acid, sulfur, tetra methyl thiuram disulphide (TMTD) and mercapto benzothiazyl disulphide (MBTS) (all commercial grades).

Styrene Butadiene Rubber (SBR 1507) (23.3\% of styrene; Mooney viscosity $=39$ ) was kindly supplied by PETROFLEX S.A, Rio de Janeiro, Brazil.

Styrene Butadiene Rubber residue (SBR-r) (23.3\% of styrene) was kindly supplied by CIAFLEX BORRACHAS LTDA, Rio Grande do Sul, Brazil.

\section{Processing and Characterization of SBR Residue}

The SBR-r residue was triturated in a knives mill. It was then sieved into three different particle sizes, ranging from 44 to $63 \mu \mathrm{m}$ (mesh 170 or $\mathrm{AB} 1$ or AE1), 64 to $88 \mu \mathrm{m}$ (mesh 250 or AB2 or AE2), and 28 to $841 \mu \mathrm{m}$ (all or $\mathrm{AB} 3$ or $\mathrm{AE} 3$ ), where $\mathrm{AB}$ and $\mathrm{AE}$ are addition at the beginning and at the end stage, respectively.

The SBR residues were evaluated by infrared spectroscopy with Fourier transform (FTIR and FTIR-ATR) and thermo gravimetric analysis (TG). The TG measurements were carried out under nitrogen atmosphere by using a Shimadzu TGA-50 at a heating rate of $10^{\circ} \mathrm{C} / \mathrm{min} . \mathrm{SiO}_{2}, \mathrm{CaCO}_{3}$ and $\mathrm{SiO} / \mathrm{CaCO}_{3}(80 / 20 \mathrm{wt} \%)$ were also evaluated by infrared spectroscopy with Fourier transform (FTIR).

\section{Compounding}

Mixing of NBR and filler was carried out using a laboratory two roll mill with a friction ratio of 1:1.5. The basic formulation used is given in Table 1. For the study of the addition order, the mix composition to which the residue was added in the end is described as AE2 and AE3. 
Table 1: Blend composition where the residue was added in the beginning (AB) and at the end (AE).

\begin{tabular}{|c|r|r|r|r|r|r|}
\hline $\begin{array}{c}\text { Blends Compositions } \\
\text { (phr) }\end{array}$ & A & AB1 & AB2 & AB3 & AE2 & AE3 \\
\hline NBR & 100 & 100 & 100 & 100 & 100 & 100 \\
ZnO & 5.0 & 5.0 & 5.0 & 5.0 & 5.0 & 5.0 \\
Stearic acid & 0.5 & 0.5 & 0.5 & 0.5 & 0.5 & 0.5 \\
Sulfur & 0.3 & 0.3 & 0.3 & 0.3 & 0.3 & 0.3 \\
MBTS $^{\text {a }}$ & 2.0 & 2.0 & 2.0 & 2.0 & 2.0 & 2.0 \\
TMTD $^{\text {b }}$ & 1.0 & 1.0 & 1.0 & 1.0 & 1.0 & 1.0 \\
SBR-r $^{\text {SB }}$ & 0 & $10-30$ & $10-30$ & $10-30$ & $10-90$ & $10-90$ \\
\hline
\end{tabular}

${ }^{a}$ Mercapto benzothiazyl disulphide ${ }^{\mathrm{b}}$ Tetra methyl thiuram disulphide

\section{Sample Preparation and Testing}

The cure characteristics of rubber compositions were determined by using a Rubber Process Analyzer (RPA 2000) at $160^{\circ} \mathrm{C}$, frequency of 1.667 $\mathrm{Hz}$ and arc degree of $0.5^{\circ}$, and by measuring optimum cure time, scorch time, minimum torque and maximum torque.

The compounds were compression-molded at $160^{\circ} \mathrm{C}$ by using an electrically- heated hydraulic press for their respective optimum cure times $\left(t_{90}\right)$. Dumbell-shaped tensile and angular tear specimens were punched out from compression-molded sheets along the mill grain direction.

The tensile properties of the compounds were measured by means of an EMIC model DL 2000, at a crosshead speed of $50 \mathrm{~mm} / \mathrm{min}$ based on ASTM D412-87, and the tear resistances of the compounds were measured at a crosshead speed of $500 \mathrm{~mm} / \mathrm{min}$ based on ASTM D624-86. Hardness was tested based on ASTM D 2240 using a Shore A durometer.

\section{Determination of Vr and Crosslink Density}

In order to estimate the extent of cross-linking, the fraction of rubber volume in the swollen network (Vr) of the rubber in toluene-swollen specimens was determined after a 7-day period through the following equation (1):

$$
\mathrm{V}_{\mathrm{r}}=\frac{(\mathrm{D}-\mathrm{fT})^{*} \rho_{\mathrm{r}}^{-1}}{(\mathrm{D}-\mathrm{fT})^{*} \rho_{\mathrm{r}}^{-1}+\mathrm{A}_{0}{ }^{*} \rho_{\mathrm{s}}^{-1}}
$$

where $\mathrm{D}$ is the weight after drying out, $\mathrm{f}$ the fraction of insoluble components, $\mathrm{T}$ the weight of sample, $\mathrm{A}_{0}$ the weight of the absorbed solvent, $\rho$ r the density of the rubber and $\rho$ s the density of the density of the solvent (George, 2000)

Crosslink density for vulcanized compositions was determined by using the swelling method. The crosslink density was calculated through the FloryRehner equation as shown in equation 2 (Mark 1987).

$$
\text { Crosslink density }=\frac{\operatorname{Ln}\left(1-\mathrm{V}_{\mathrm{r}}\right)+\mathrm{V}_{\mathrm{r}}+\chi * \mathrm{~V}_{\mathrm{r}}}{\left(0,5 * \mathrm{~V}_{\mathrm{r}}-\mathrm{V}_{\mathrm{r}}^{\frac{1}{3}}\right) * 2 \mathrm{~V}_{0}}
$$

Where $\mathrm{Vr}$ is the volume fraction of rubber in swollen vulcanization, $\mathrm{V}_{0}$ is the molar volume of solvent used (toluene $=106.2 \mathrm{~cm}^{3} / \mathrm{mol}$ ), $\chi$ the polymer-solvent interaction parameter (NBR-toluene $=0.472$ ), and $\rho$ is the polymer density.

\section{RESULTS AND DISCUSSION}

\section{Characterization of SBR Residues}

The basic components of SBR residue were identified with the help of FTIR analysis. The SBR rubber was determined by ATR absorbance peaks at 2920 and $2850 \mathrm{~cm}^{-1}$ attributed to the $\mathrm{CH}$ stretching of aromatic rings. The absorption at $1600 \mathrm{~cm}^{-1}$ was due to the stretching vibration of the $\mathrm{CH}_{2}$ and $\mathrm{CH}_{3}$. The absorption at 966 and $699 \mathrm{~cm}^{-1}$ was attributed to aromatic C-C stretching. Others peaks at 912 and $757 \mathrm{~cm}^{-1}$ were attributed to trans 1,4 structure and $\gamma_{\mathrm{CH}}$ of the single substituted benzene ring and the $\mathrm{CH}$ out of plane deformation, respectively.

Figure 1 shows the FTIR-ATR spectrum. As it can be visualized, the presence of calcium carbonate was assigned by bands at 1422 and $874 \mathrm{~cm}^{-1}\left(\mathrm{CO}_{3}^{-2}\right.$ stretching and $\mathrm{CO}_{3}^{-2}$ out of plane deformation, respectively). Finally, silica was detected due to bands at 3450 and at $1120 \mathrm{~cm}^{-1}$, the characteristic absorption band attributed to the $\mathrm{SiO}$ stretching.

Other chemical expanding agents, curatives, etc. could not be identified by FTIR-ATR analysis because of their reaction and decomposition during processing.

The SBR residue was also submitted to thermogravimetric analysis (TG) in order to determine the amount of rubber and inorganic material present therein. The decomposition of the residue occurred in two steps, as shown in Figure 2. The first step started at around $450^{\circ} \mathrm{C}$, corresponding to $26 \% \mathrm{wt}$ and was attributed to SBR decomposition. The second step started at around $680^{\circ} \mathrm{C}$ to $750^{\circ} \mathrm{C}$, and was attributed to inorganic filler decomposition, in this case corresponding to $\mathrm{CaCO}_{3}$ decomposition. The SBR (23.3\% styrene) curve is shown for comparative analysis with SBR-r samples. 


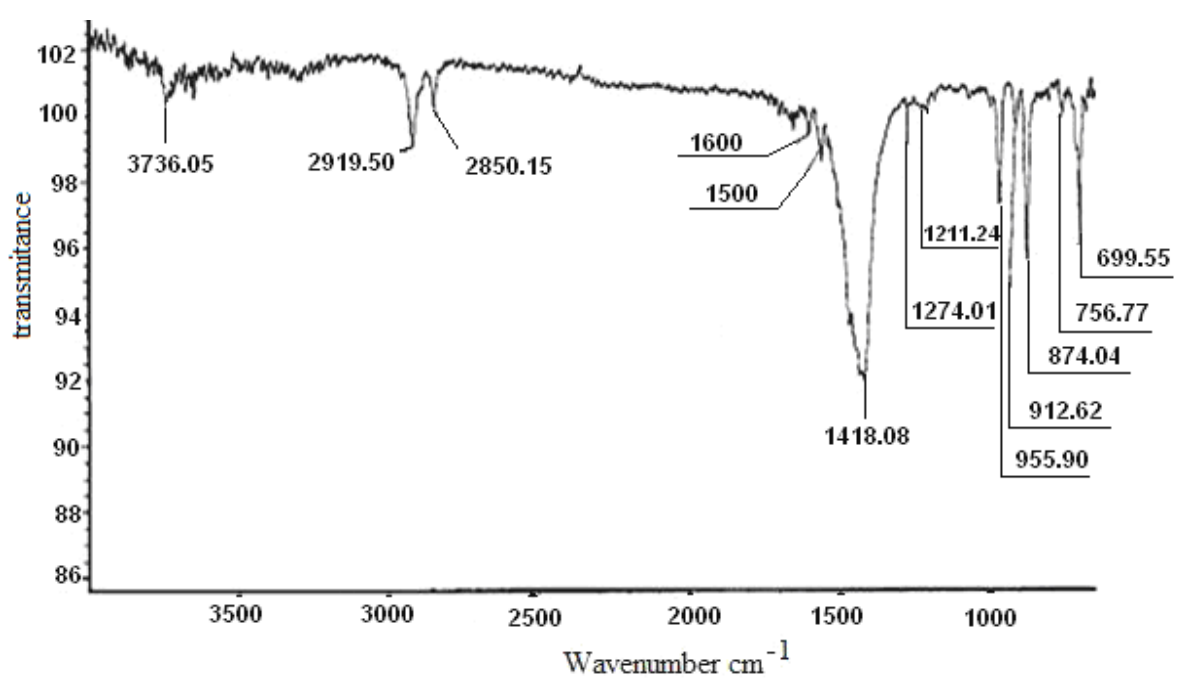

Figure1: FTIR spectra of SBR residue

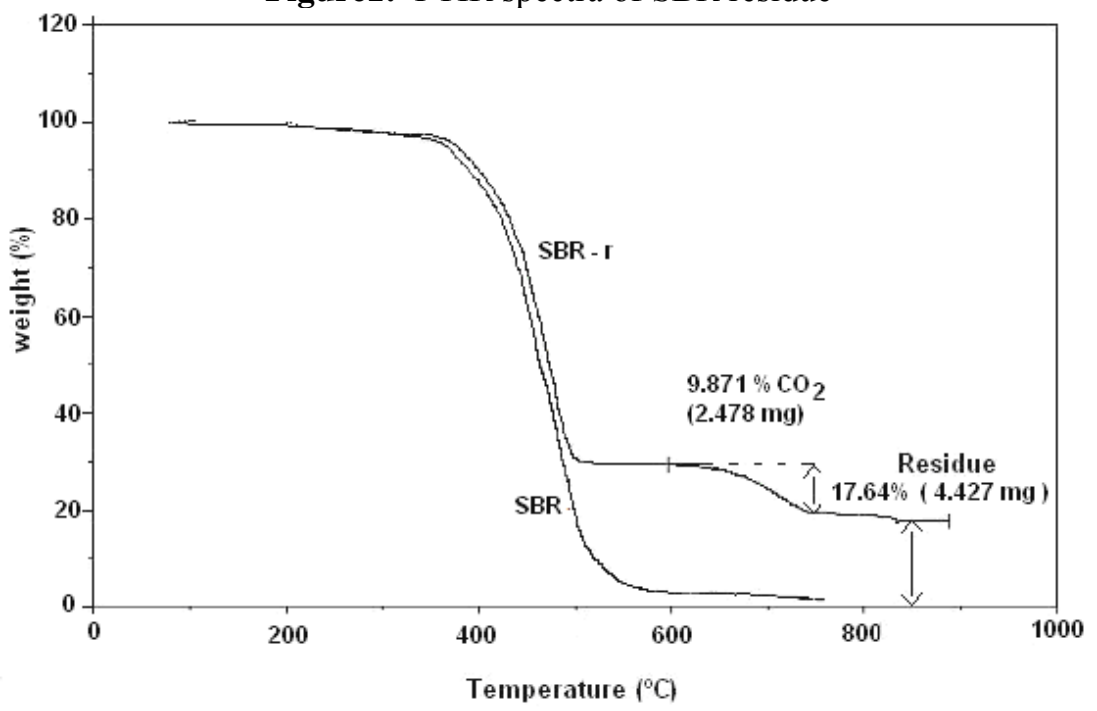

Figure 2: Thermogravimetric curve of SBR and SBR residue

\section{Addition Order}

Filler incorporation during rubber processing can be done in several ways, according to its nature. Therefore, this work studied two different orders of SBR-r addition. The first method adopted was the addition of SBR-r after ten minutes of processing NBR pure gum in the roll mill, and the second one was its addition at the final stage of composition processing, i.e., after the incorporation of all curatives in NBR gum.

The efficiency of these methods was evaluated regarding their mechanical properties. For this study, the compositions $\mathrm{AB} 2, \mathrm{AB} 3, \mathrm{AE} 2$ and $\mathrm{AE} 3$ were used. Table 2 presents the results obtained. As can be seen, the values of tensile strength and elongation at break were better for the two samples in which SBR residues were added at the final stage: AE2 and AE3.
The SBR-r contains some additives such as vulcanizing agents and inorganic fillers from formulation. Theses compounds can migrate to NBR phases due to differences in solubility parameters between rubbers. The presence of these components can affect the crosslinking of NBR and the mechanical properties of the mixes. When the vulcanizers (sulphur and accelerators) are added before the SBR-r, their distribution in NBR phases is favoured. Subsequently, when the residue is added at the final stage, the transfer of cure agents of SBR-r phases is reduced by the presence of a cure system in the NBR matrix.

This kind of behavior can also be explained by the reduction of competition for curatives between NBR and SBR-r when the residue was added at the end stage, resulting in a better crosslinked rubber matrix. 
Table 2: Effect of size particle and different order of addition of SBR-r on the tensile strength, elongation at break and crosslink density of blends.

\begin{tabular}{|l|r|r|r|r|r|rr|r|r|}
\hline & \multicolumn{1}{|c|}{ A } & \multicolumn{2}{|c|}{ AB1 } & \multicolumn{2}{|c|}{ AB2 } & \multicolumn{2}{|c|}{ AB3 } & AE2 & AE3 \\
\hline p.h.r & 0 & 10 & 30 & 10 & 30 & 10 & 30 & 30 & 30 \\
$\sigma^{\mathrm{a}}$ & 1.18 & 1.28 & 1.38 & 1.18 & 1.16 & 1.28 & 1.44 & 1.07 & 1.54 \\
$(\mathrm{MPa})$ & \pm 0.04 & \pm 0.06 & \pm 0.04 & \pm 0.02 & \pm 0.03 & \pm 0.03 & \pm 0.03 & \pm 0.04 & \pm 0.06 \\
$\varepsilon$ & 415 & 389 & 397 & 371 & 477 & 380 & 441 & 439 & 415 \\
$(\%)^{\mathrm{b}}$ & \pm 21 & \pm 32 & \pm 15 & \pm 9 & \pm 9 & \pm 25 & \pm 10 & \pm 38 & \pm 20 \\
$v\left(\mathrm{~mol} / \mathrm{cm}^{3}\right)^{\mathrm{C}} \mathrm{X}$ & 3.6884 & 3.7456 & 4.7652 & 3.6568 & 4,7185 & 3.7635 & 5.2945 & 4.8769 & 5.3341 \\
$10^{5}$ & \pm 0.011 & \pm 0.012 & \pm 0.013 & \pm 0.013 & \pm 0.012 & \pm 0.022 & \pm 0.011 & \pm 0.021 & \pm 0.023 \\
\hline
\end{tabular}

${ }^{\mathrm{a}}$ Tensile strength at break, ${ }^{\mathrm{b}}$ elongation at break, ${ }^{\mathrm{C}} \mathrm{Crosslink}$ density

\section{Size and Filler Loading}

The best results for mechanical properties were obtained when SBR-r was added at the end stage. For the study of filler loading and particle size on rheometric and mechanical properties, the above method of addition was adopted. Figure 3 and 4 show the effect of SBR-r loading on the optimum cure time $\left(t_{90}\right)$ and scorch time $\left(t_{s 1}\right)$ of NBR compositions with three different particle sizes (AE1, AE2, and AE3); the values were presented in Table 3 .

All series of compositions showed a decreasing trend when filler loading increased. In fact, as the loading of SBR-r residues increased, both the transference and the availability of the unreacted accelerator for NBR phases increased, which led to an increasing rate of vulcanizing reaction. Then, reductions in curing characteristics such as optimum cure time and scorch time were observed.

Other researchers observed a similar trend in other rubber residue containing composites and related this to residual curatives in the waste rubber sample, such as sulphur and accelerators used in the original formulations (Hong, 2002).

Table 3: Effect of size particle of SBR-r on the rheometric parameters with filler loading for NBR loaded for (AE3).

\begin{tabular}{|l|r|r|r|r|r|r|r|}
\hline & A & \multicolumn{2}{|c|}{ AE1 } & \multicolumn{2}{|c|}{ AE2 } & \multicolumn{2}{c|}{ AE3 } \\
\hline p.h.r & 0 & 10 & 30 & 10 & 30 & 10 & 30 \\
$\mathrm{M}_{\mathrm{H}}{ }^{\mathrm{a}}(\mathrm{dN} . \mathrm{m})$ & 11.6 & 11.4 & 11.8 & 11.4 & 11.3 & 11.6 & 12.8 \\
$\mathrm{M}_{\mathrm{L}}{ }^{\mathrm{b}}(\mathrm{dN} . \mathrm{m})$ & 0.85 & 0.86 & 0.98 & 0.80 & 0.85 & 0.99 & 1.1 \\
$\mathrm{t}_{90}{ }^{\mathrm{c}}(\mathrm{min})$ & 5.8 & 5.2 & 5.0 & 6.3 & 5.7 & 5.3 & 4.9 \\
$\mathrm{t}_{\mathrm{s} 1}{ }^{\mathrm{d}}(\mathrm{min})$ & 2.5 & 2.1 & 1.6 & 2.4 & 2.2 & 2.1 & 1.5 \\
\hline
\end{tabular}

${ }^{\mathrm{a}}$ maximum torque, ${ }^{\mathrm{b}}$ minimum torque, ${ }^{\mathrm{c}}$ optimum cure time, ${ }^{\mathrm{d}}$ scorch time

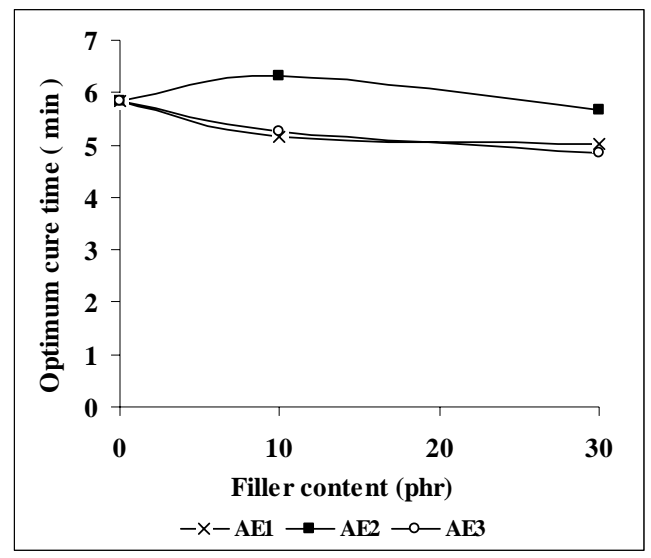

Figure 3: Variation of optimum cure time of NBR compounds with particle size and filler loading.

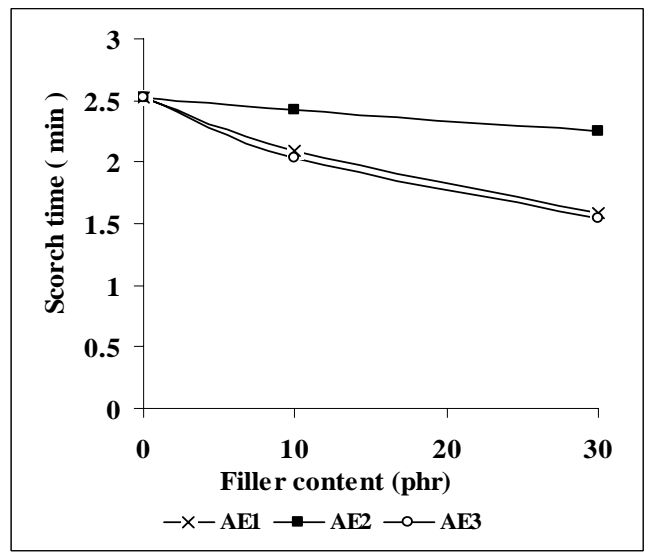

Figure 4: Variation of scorch time of NBR compounds with particle size and filler loading. 
In relation to the effect of the particle size, the decrease in optimum cure time and scorch time were observed for the AE3 blend, Table 3. The size of particles composing the AE3 mix was in the 28 to $841 \mu \mathrm{m}$ range, whereas the particle size range of the AE2 sample was 64 to $88 \mu \mathrm{m}$ and of the AE1 sample was 44 to $63 \mu \mathrm{m}$. The AE3 sample had both large $(841 \mu \mathrm{m})$ and small particles $(28 \mu \mathrm{m})$, and it was the presence of these small particles that may have increased interaction between energy charges (SBR$\mathrm{R}$ ) and the matrix (NBR), owing to an increase in the superficial contact area between the phases.

Thus, as particle size decreased, there was an increase in surface area, which favored the curative diffusion from residue to virgin rubber.

Table 3 compares the torque values for NBR rubber as functions of the SBR-r content and size. The minimum $\left(\mathrm{M}_{\mathrm{L}}\right)$ and maximum torque $\left(\mathrm{M}_{\mathrm{H}}\right)$ increased with the addition of SBR-r, which was related to the increase in system viscosity because of the presence of cross-linked material in the SBR-r. The increase of $\mathrm{M}_{\mathrm{H}}$ may also have been related to the increase in crosslink degree promoted by residual curatives in the SBR-r.
Table 4 also shows the variation of rheometric characteristics of filler loading of NBR loaded with size-3 filler (AE3). The minimum torque $\left(\mathrm{M}_{\mathrm{L}}\right)$ was affected by an increase in the SBR-r loading rate. This indicates that it is more difficult to process compounds that contain SBR-r compared to compounds without SBR-r. The apparent reason for minimum torque increase is that cross-linked SBR-r does not easily flow to the matrix and this results in higher viscosity of the blends. A significant increase in the maximum torque was dependent on the SBR-r content, suggesting an increase in crosslink density.

The increase in crosslink degree was confirmed by swelling experiments in toluene. The rubber volume in the swelling network $(\mathrm{Vr})$ rose in accordance with the SBR-r amount due to swelling restrictions imposed by the crosslinked network of the NBR matrix. Indeed, crosslink density values of NBR compositions continually increased with SBR-r amount. This trend also confirmed the values of maximum torque $\left(\mathrm{M}_{\mathrm{H}}\right)$, known to be a function of the crosslinking degree and filler loading.

Tensile properties of NBR/SBR-r are presented in Table 5 and Figure 5, as a function of SBR-r content.

Table 4: The variation of rheometric characteristics with filler loading for NBR loaded with size 3 filler (AE3).

\begin{tabular}{|c|c|c|c|c|c|}
\hline SBR-r content (phr) & $\begin{array}{c}t_{90} \\
(\mathrm{~min})\end{array}$ & $\begin{array}{c}t_{\mathrm{s} 1} \\
(\mathrm{~min})\end{array}$ & $\begin{array}{c}M_{H} \\
\text { (dN.m) }\end{array}$ & $\begin{array}{c}\mathbf{M}_{\mathrm{L}} \\
\text { (dN.m) }\end{array}$ & $\begin{array}{c}\text { CRI } \\
\left(\mathrm{min}^{-1}\right)\end{array}$ \\
\hline 0 & 5.83 & 2.52 & 11.57 & 0.85 & 30.21 \\
\hline 10 & 5.45 & 2.08 & 11.60 & 0.85 & 29.67 \\
\hline 30 & 4.85 & 1.54 & 12.75 & 1.09 & 30.21 \\
\hline 50 & 3.65 & 0.89 & 13.77 & 1.59 & 36.23 \\
\hline 70 & 3.91 & 0.82 & 15.01 & 1.92 & 32.36 \\
\hline 90 & 3.64 & 0.73 & 15.50 & 2.12 & 34.24 \\
\hline
\end{tabular}

Table 5: Mechanical properties of the compounds of NBR loaded with size 3 filler (AE3).

$\left.\begin{array}{|c|c|c|c|c|}\hline \begin{array}{c}\text { SBR-r } \\ \text { (phr) }\end{array} & \begin{array}{c}\text { Tensile strength } \\ \text { at break (MPa) }\end{array} & \begin{array}{c}\text { Elongation } \\ \text { at break (\%) }\end{array} & \begin{array}{c}\text { Tear strength } \\ \text { (N.mm) }\end{array} \\ \hline 0 & 1.18 & 415 & 39.3 \\ \text { (Shore A) }\end{array}\right)$

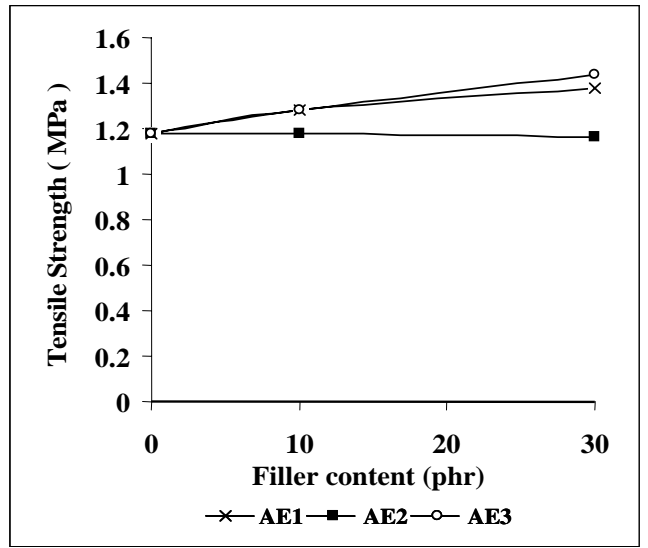

Figure 5: Effect of the filler size and loading on the tensile strength of NBR compounds. 
The addition of SBR-r resulted in an increase of the ultimate tensile strength up to the limit of $70 \mathrm{phr}$. Beyond this amount, the formation of filler agglomerates may occur. It has been extensively reported in the literature that poor stress transfer at the filler-polymer interphase discontinuity creates particulate-filled composites, which in their turn generate a weaker structure. Agglomeration of the filler particles and dowelling of the polymer at the interphase aggravate the situation by creating stress concentration points, which account for the weakness in the composite.

Figure 5: Effect of the filler size and loading on the tensile strength of NBR compounds.

Elongation at break $(\mathrm{Eb})$ showed a slight increase of up to $30 \mathrm{phr}$. Further addition of SBR-r resulted in lower values of $\mathrm{Eb}$. The decrease in elongation at break of vulcanizates containing SBR-r indicated hindrance by SBR-r of deformability of the NBR matrix. It should be remarked that SBR-r was vulcanizated and contained inorganic fillers such as silica and calcium carbonate.

The hardness values also joined the same trend exhibited by maximum torque $\left(\mathrm{M}_{\mathrm{H}}\right)$, being a function of crosslink degree and filler loading in rubber composition. Table 5 shows the variation of hardness on filler loading and size. The three particle sizes employed resulted in compositions with higher hardness as SBR-r amount increased. Again, this trend confirms the values of $\mathrm{M}_{\mathrm{H}}$ and crosslink density.

Tear strength of NBR compositions was also studied. There was a little increase upon SBR-r addition, suggesting a good adhesion between filler and NBR matrix, Table 5. However, the addition of

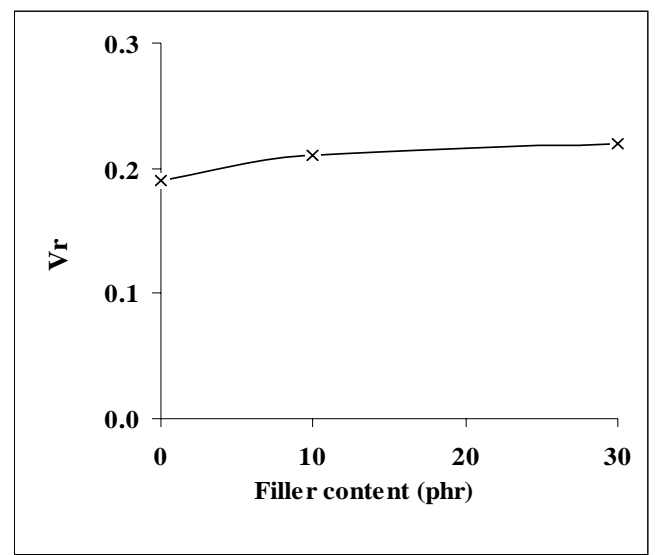

Figure 6: Effect of the loading of filler on the $\mathrm{Vr}$ for NBR loaded with size 3 filler (AE3). a compatibilizer was clearly necessary to improve this adhesion. Moreover, by comparing the three particle sizes, the largest particle size SBR-r were seen to promote better mechanical properties, as they were more reinforcing. This tendency opposes the conventional rules for filler-polymer interaction with respect to particle size. Nevertheless, the filler studied in the article was not an inorganic one, thus involving other questions besides particle size. As discussed earlier, curative diffusion phenomena also play an important role in polymer fillers. As particle size decreases, the surface area increases, accelerating the migration of curatives and consequently weakening the matrix. Owing to these particle sizes, AE3 showed better mechanical properties over other compositions.

\section{Swelling Studies}

Figure 6 shows the rubber volume in the swollen network vulcanization of NBR compounds with various SBR-r residue (AE3) contents in toluene. The Vr values increased with SBR-r concentration. The increase in $\mathrm{Vr}$ values seemed to vary depending on the extent of crosslinking, as the restriction to swelling increased with network formation. From the above results, it is clear that crosslink density increases with SBR-r content.

Figure 7 presents the variations of crosslink density for NBR compounds loaded with size 3 filler (AE3). It can be observed that the crosslink density increased significantly with an increase in SBR-r loading. Higher crosslink density leads to improved mechanical properties, which also explains the increase in maximum torque.

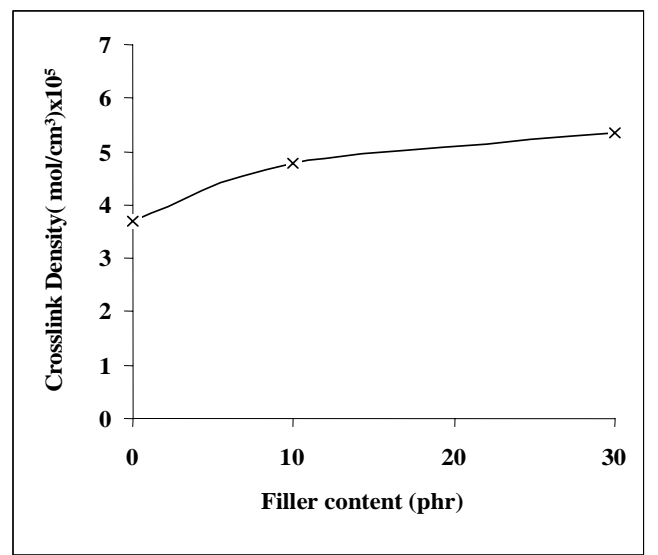

Figure 7: Effect of the loading of filler on the crosslink density for NBR loaded with size 3 filler (AE3). 


\section{CONCLUSIONS}

The use of SBR-r residues as potential fillers in NBR rubber is very appealing because of the simplicity of the technique. Studies of addition order showed that the values of tensile strength and elongation at break were better for the samples in which SBR-r residues were added in the end stage. The morphology of particle size and size distribution were analyzed and, by increasing filler loading, a reduction in optimum cure and scorch time was observed. Up to $70 \mathrm{phr}$ filler loading, the tensile strength showed good improvement. Size 3 filler exhibits superior tensile strength over others. Hardness values and tear strength values were found to increase with increasing filler content. This observation was supported by higher crosslink density.

\section{ACKNOWLEDGEMENT}

The authors thank CNPq, FAPERJ, Nitriflex S.A Ind. \& Com. and Instituto Nacional de Tecnologia (INT).

\section{REFERENCES}

Acetta, A. and Vergnaud J. M., Upgrading of Scrap Rubber Powder by Vulcanization Without New, Rubber Chemical Technology, 54, p. 302-310 (1981).

Azir, Y., Utilization of Reclaimed Rubber from Latex Glove Factory Rejects, Paper presented at Polymer 90, Kuala Lumpur, Malaysia, 23 September (1990).

Biddulph, M. W., Mixing in Water Elutriators, Resources Conservation and Recycling, 1, p. 5562 (1977).

Braton, N. R. and Koutsky, J. A., A New Recycling Technology: Compression Molding of Pulverized Rubber Waste in the Absence of Virgin Rubber, Chemical Engineering News, 52, p 21-26, (1974).

Claramma, N. M., Thomas, K. T. and Thomas, E. V., Recycling of Natural Rubber latex Waste and Its Interaction in Epoxidised Natural Rubber, Paper presented at the Rubber Conference, Jamshedpur, 6-8 November (1986).

Creasey, J. R. and Wager, M. P., Rubber Composition, Particularly For Tire Tread, Rubber Age, 10, No. 100, 72-86 (1968).

Fang, Y., Zhan, M. and Wang, Y., The Status of Recycling of Waste, Rubber Materials and Design, 22, p. 123-127 (2001).
Fujimoto, K., Nippon Gomu Kyokaishi, Reagents for Heat Activated Polymer Crosslinking - Patent 6355838, 52, 281-287, (1979).

Fujimoto, K., Nishi, T. and Okamoto, T., Devulcanisation of NB Based Latex Products For Tyre Applications, International Polymer Science and Technology, No. 8, p. T/30 (1981).

George, J., Varughese, K. T. and Thomas S., Dynamically Vulcanized Thermoplastic Elastomer Blends of Polyethylene and Nitrile, Rubber Polymer, 41, p. 1507-1512 (2000).

Harshaft, A. A., Solid Waste Treatment Technology, Environment Science Technology, 6, p. 412-421 (1972).

Hong, C. K. and Isayev, A. I., Blends of Ultrasonically Devulcanized and Virgin Carbon Black Filled NR, Journal of Material Science, 37, p. 385-388 (2002).

Isayev, A. I., Chen, J. and Tukachinsky A., Novel Ultrasonic Technology for Devulcanization of Waste Rubbers, Rubber Chemical Technology, 68 , p. 267-280 (1995).

Isayev, A. I., Yushanov, S. P. and Chen, J., Ultrasonic Devulcanization of Rubber Vulcanizates. I. Process Model, Journal of Applied Polymer Science, 59, p. 803-813 (1996).

Lee, T. C. P. and Millem, Curable Liq. Epoxy Or Mercaptan Terminated Block Copolymers - Obtd. By Reacting Epoxy Terminated Polymer With a Mercaptan Terminated Polymer, With One Component in Stoichiometric Excess, W. S., U.S. Patent, 4, No. 046, p. 834-854 (1977).

Levin, V. Y., Kim, S. H. Isayev, A. I., Massey, J. and Meerwall, E., Ultrasound devulcanization of sulphur-vulcanized SBR: crosslink density and molecular mobility, Rubber Chemical Technology, 69, p. 104-114 (1996).

Mark, J. E., Experimental Determinations of Crosslink Densities, Rubber Chemical Technology, 55, 3, p. $762-779$ (1982).

Mathew, G., Singh, R. P., Nair, N. R. and Thomas. $\mathrm{S}$, Recycling of Natural Rubber Latex Waste and Its Interaction in Epoxidised Natural Rubber, Polymer, 42, p. 2137-2165 (2001).

Oliphant, K. and Baker, W. E., The Use of Cryogenically Ground Rubber Tires as a Filler in Polyolefin Blends, Polymer Engineering and Science, 3, p. 33, 166 (1993).

Phadke, A. A. and Kuriakose, B., Rheological Behaviour of Cryo-Ground Rubber-Natural Rubber Blends, Kautsch Gummi Kunststoff, 8, 38, p. 694-697 (1985).

Phadke, A. A., Bhattacharya, A. K., Chakraborthy, S. K. and De, S., Studies of Vulcanization of 
Reclaimed Rubber, Rubber Chemical Technology, 56, 4, p.726-735 (1983).

Phadke, A. A., Chakraborthy, S. K. and De S. K., Cryoground Rubber-Natural Rubber Blends, Rubber Chemical Technology, 57, p. 19-33 (1984).

Rajalingam, P., Sharpe, J., Baker, W. E., Ground Rubber Tire/Thermoplastic Composites: Effect of Different Ground Rubber Tires, Rubber Chemical Technology, 66, p. 664-672 (1993)

Ratcliffe, A., Bioreactors and Bioprocessing for Tissue Engineering, Chemical Engineering Science, 79, p. 62-71 (1977).

Sakai, R. H., Placas Expandidas em Eva para Indústria Calçadista, Tecnicouro, 6, 13, p. 39-42 (1991).

Saxena, N. S., Pradeep, P., Mathew. G., Thoma, S., Gustafsson, M. and Gustafsson. S. E., Thermal conductivity of styrene butadiene rubber compounds with natural rubber prophylactics waste as filler, European Polymer Journal, 9, 35, p. 1687-1693 (1999).

Sombatsompop, N., Dynamic Mechanical Properties of SBR and EPDM Vulcanisates Filled with Cryogenically Pulverized Flexible Polyurethane Foam Particles, Journal of Applied Polymer
Science, 74, p. 1129-1139 (1999).

Tatibouët, J., Gendron, R. and Haïder, L., Ultrasonic Characterization Performed during Chemical Foaming of Cross-linked Polyolefins, Polym. Test., 2, 23, p. 125-130 (2004)

Tukachinsky, A., Schworm, D. and Isayev, A. I., Devulcanization of Waste Tire Rubber By Powerful Ultrasound, Rubber Chemical Technology, 69, p. 92-103 (1996).

Yasuda, H., Marsh, C., Brandt, S. and Reilly, C. N., ESCA Study of Polymer Surfaces Treated by Plasma, Journal of Polymer Science A, Polymer Chemistry, 15, p. 991-1019 (1977).

Yu, D. W., Xanthos M. and Gogos, C. G., Peroxide Modified Polyolefin Blends - Part II: Effects on LDPE/PP Blends with Polymer Components of Dissimilar Initial Viscosities, Adv. Polymer Techn., 11, p. 295-319 (1992).

Zhan, M., Fang, Y. and Wang Y., The Status of Recycling of Waste Rubber, Materials \& Design, 22, 123-128 (2001).

Zimmermman, C. J., Ryde, N., Kally, N., Partch, R. E. and Matijevie, E., Plasma Modification of Polyvinyltoluene and Polystyrene Latices, J. Material Research, 6, p. 855-860 (1991). 